\title{
Modeling and Nonlinear Control of a Wind Turbine System Based on a Permanent Magnet Synchronous Generator Connected to the Three-phase Network
}

\author{
Yasser Boussairi ${ }^{1}$, Abdelmajid Abouloifa ${ }^{2}$, Ibtissam Lachkar ${ }^{3}$, Abdellatif Hamdoun ${ }^{4}$, \\ Chaouqi Aouadi ${ }^{5}$ \\ ${ }^{1,2,4,5}$ LTI Lab, Faculty of Sciences Ben M'sik, University Hassan II of Casablanca, BP 7955 Casablanca, Morocco \\ ${ }^{3}$ LRI Lab, ENSEM of Casablanca, University Hasan II of Casablanca, BP 7955 Casablanca, Morocco.
}

\begin{tabular}{l} 
Article Info \\
\hline Article history: \\
Received Aug 26, 2017 \\
Revised Dec 17, 2017 \\
Accepted Jan 18, 2018 \\
\hline Keyword: \\
AC-DC-AC converter \\
Backstepping \\
Matlab/simulink \\
MPPT \\
Permanent magnet synchronous \\
generator (PMSG) \\
PFC
\end{tabular}

\begin{abstract}
This article presents nonlinear control of wind conversion chain connected to the grid based on a permanent magnet synchronous generator. The control objectives are threefold; i) forcing the generator speed to track a varying reference signal in order to extract the maximum power at different wind speed (MPPT); ii) regulating the rectifier output capacitor voltage; iii) reducing the harmonic and reactive currents injected in the grid. This means that the inverter output current must be sinusoidal and in phase with the AC supply voltage (PFC). To this end, a nonlinear state-feedback control is developed, based on the average nonlinear model of the whole controlled system. This control strategy involves backstepping approach, Lyapunov stability and other tools from theory of linear systems. The proposed statefeedback control strategy is tested by numerical simulation which shows that the developed controller reaches its objectives.
\end{abstract}

Copyright $\odot 2018$ Institute of Advanced Engineering and Science. All rights reserved.

Corresponding Author:

Yasser Boussairi,

LTI Lab, Faculty of Sciences Ben M'sik,

University Hassan II of Casablanca, BP 7955 Casablanca,

Bd elharti moulay rachid casablanca Morocco

Email: yasserboussairi@gmail.com

\section{INTRODUCTION}

In this work, we have interested wind energy. Till now, there are two types of wind turbines: the wind speed fixed directly connected to the grid by the stator and variable speed wind turbines commissioned by the stator and the rotor by means of electronic power converters [1]. Thanks to the numerous advantages it has compared to other types of electrical machines (robustness, maintenance, price), the permanent magnet synchronous machine is interesting for use as a generator coupled to a wind turbine [2], [3], [4].

In this article, we will look at the study of a complete chain of wind energy conversion shown in Figure 1 which includes a synchronous permanent magnet generator that converts wind energy into an output voltage whose amplitude and frequency vary depending on the wind speed and AC/DC/AC converters which connects of the generator and the network via a LCL filter.

In order, nonlinear or having non-constant parameters systems, conventional control laws may be inadequate because they are not strong especially when the demands on accuracy and other dynamic characteristics of the systems are strict. We must use control laws insensitive to parameter variations, to disturbance and nonlinearities. For this purpose, several tools are available in the literature, such as proportional integral (PI) controllers [5], [6], [7]. this mode of control is insufficient to control of such complex system where the parameters are not stable over time, other research interested by advanced method 
like sliding mode [8], [9]. but also, this technique shows a chattering phenomenon which has a negative effect in the mechanical part of the machine, moreover, platitude approach is described in another article [10].

In this article, we present a backstepping to control power converters associated with the generator, The Backstepping approach is a systematic and recursive design methodology for nonlinear feedback control [11]. The control to apply in different parts of the system. The generator-side converter is mainly used to control the generator speed to extract the maximum output power at various wind speeds [12], [13], the network-s ide converter is mainly used to control the reactive power on the one hand and maintain tension in the DC bus capacitor of the constant value and the make the current output of the inverter in the phase withe the grid voltage.

The rest of the paper is organized $d$ as follows: the model mathematical of the w hole system is presented by the equation of states in Section II; Section III describes in details the proposed control strategy based on backstepping approach for the system studied, while in Section IV gives simulation results demonstrating the good performance of the proposed method in MATLAB/Simulink, then a conclusion at the end of paper.

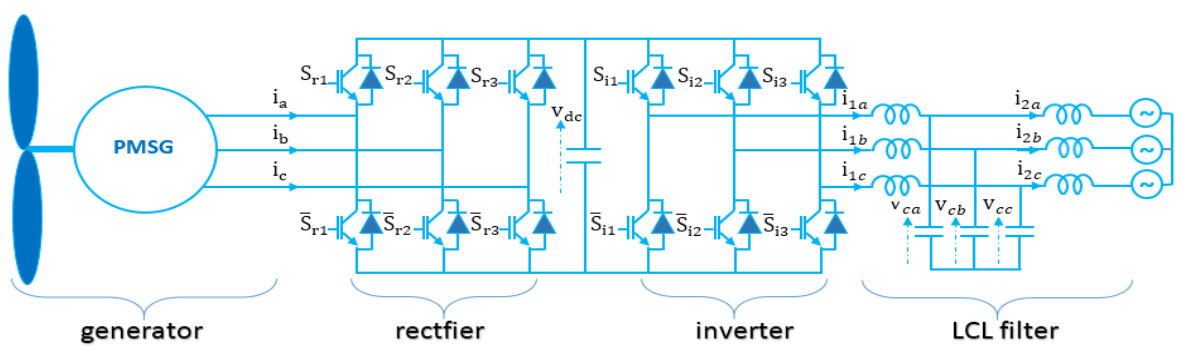

Figure 1. Architecture of the Wind Power System

\section{MODELING OF THE WIND SYSTEM}

\subsection{Generator Modeling}

To simplify the system of equations with variable coefficients, a model in the Park reference of this machine will be used. The Park reference is simpler to manipulate because the electrical quantities evolve like continuous magnitudes. One can switch from one to the other marker using transit matrices.

Since the voltages are the input variables, the output quantities (currents) can be expressed as a function of these, the state model of the synchronous machine, expressed in the rotating $\mathrm{d}-\mathrm{q}$ reference frame linked to the rotor, is the following [14]:

$$
\begin{aligned}
& \&=\frac{p \phi_{f}}{j} x_{2}-\frac{f}{j} x_{1}-\frac{1}{J} T_{l} \\
& \&=-\frac{R_{s}}{L_{q}} x_{2}-p \frac{L_{d}}{L_{q}} x_{1} x_{3}-p \frac{1}{L_{q}} \phi_{f} x_{1}+\frac{1}{L_{q}} v_{d c} u_{1} \\
& \&=-\frac{R_{s}}{L_{d}} x_{3}+p \frac{L_{d}}{L_{q}} x_{1} x_{2}+\frac{1}{L_{d}} v_{d c} u_{2}
\end{aligned}
$$

where: $x_{1}=\bar{\Omega} ; x_{2}=\overline{i_{q}} ; x_{3}=\overline{i_{d}} ; x$ an averaging value over a cutting period of a real signal $\bar{x}$.

$R_{s}$ resistance of the stator windings $\left(L_{d}, L_{q}\right)$ are $\mathrm{d}$ and q axis inductances $\left(i_{d}, i_{q}\right)$ are the dq components of the stator current, $\phi_{f}$ amplitude of the flux induced by the permanent magnets of the rotor in the stator phases , $\mathrm{p}$ number of pole pairs, $\mathrm{j}$ combined inertia of rotor and load, $T_{l}$ shaft mechanical torque , $\mathrm{f}$ combined viscous friction of rotor and load, $\omega$ angular velocity of the rotor $\left(v_{q}, v_{q}\right)$ denote the averaged stator voltage in dq- coordinate, these voltages are expressed in function of the corresponding control action: 


$$
\left[\begin{array}{ll}
v_{d} & v_{q}
\end{array}\right]^{T}=v_{d c}\left[u_{1} u_{2}\right]^{T}
$$

\subsection{Modeling the Inverter and Filter Association}

After presenting the model of the machine, we will expose the complete drive system where the controlled inverter is associated with the LCL filter connected to the network [15], [16]:

$$
\begin{aligned}
& {\left[\&_{4 d q}\right]=-\frac{r_{2}}{L_{2}}\left[x_{4 d q}\right]+\frac{1}{L_{2}}\left[x_{5 d q}\right]-\frac{1}{L_{2}}\left[v_{g d q}\right]+M_{2} x_{4 d q}} \\
& {\left[\&_{d d q}\right]=-\frac{1}{C}\left[x_{6 d q}\right]-\frac{1}{C}\left[x_{5 d q}\right]+C M x_{5 d q}} \\
& {\left[\&_{d d q}\right]=-\frac{r_{1}}{L_{1}}\left[x_{6 d q}\right]+\frac{1}{L_{1}}\left[u_{d q}\right]-\frac{1}{L_{1}}\left[x_{5 d q}\right]+M_{1} x_{6 d q}} \\
& \&=\frac{1}{C_{d c}}\left(i_{r}-i_{o}\right)
\end{aligned}
$$

where: $x_{4}=\overline{i_{2}} ; x_{5}=\overline{v_{c}} ; x_{6}=\overline{i_{1}} ; x_{7}=\overline{v_{d c}}: x$ an averaging value over a cutting period of a real signal $\bar{x}$.

$$
\text { and } M_{1}=L_{1} M ; M_{2}=L_{2} M ; M=\left[\begin{array}{cc}
0 & \omega \\
-\omega & 0
\end{array}\right]
$$

$L_{1}$ and $L_{2}$ the self-inductances $\mathrm{r} 1$ and $\mathrm{r} 2$ are its parasitic resistances, $\left(i_{1 d}, i_{1 q}\right),\left(i_{2 d}, i_{2 q}\right)$ are the dqcomponents of the current flowing the inductors $L_{1}$ and $L_{2}$ respectively. $\left(v_{c d}, v_{c q}\right) ;\left(v_{g d}, v_{g q}\right),\left(v_{o d}, v_{o q}\right)$ are the dq-components of the capacitor and grid voltage and in the output of inverter respectively. The inverter is featured by the fact that the grid d- and q-voltage can be controlled independently. In fact, one has:

$$
\left[\begin{array}{ll}
v_{\text {od }} & v_{o q}
\end{array}\right]^{T}=v_{d c}\left[\begin{array}{ll}
u_{d} & u_{q}
\end{array}\right]^{T}
$$

where: $u_{d}, u_{q}$ represent the average d-and q-axis of the 3-phase duty ratio system $\left(u_{a}, u_{b}, u_{c}\right)$.

\section{DESIGN CONTROL}

\subsection{Control Objectives}

In this work, we are interested in ordering a wind energy conversion chain to produce electrical energy and inject it into the grid. To achieve this objective, the backstepping approach associated with the Lyapunov tools is used to guarantee the asymptotic stability of the closed loop system. From a control point of view, this is expressed into the following three objectives: i) Speed control: Force the speed of the generator to follow a reference signal varies. ii) PFC: the current injected into the network must be sinusoidal and in phase with the AC supply voltage. iii) Controlling the voltage $v_{d c}$ of the DC bus voltage to a reference given $v_{d c r e f}$. This is usually set to a constant value equal to the nominal voltage of the inverter input.

\subsection{Regulator Design for Synchronous Generator}

The control strategy adopted uses cascaded loops, two internal loops for controlling the currents of axis $\mathrm{d}$ and $\mathrm{q}$ and an external loop for controlling the speed of the generator. Usually, the d-axis current must be regulated to zero in order to keep the flux constant in the air gap of the machine [17]. The q-axis current must track a reference signal from the external speed loop [18]. To solve this tracking problem, the following errors are defined:

$$
e_{1}=x_{1}^{*}-x_{1}
$$




$$
\begin{aligned}
& e_{2}=x_{2}^{*}-x_{2} \\
& e_{3}=x_{3}^{*}-x_{3}
\end{aligned}
$$

Using the equations (1-3) we get the dynamics errors following:

$$
\begin{aligned}
& \&=x_{1}^{*}-\frac{p \phi_{f}}{j} x_{2}-\frac{f}{j} x_{1}-\frac{1}{J} T_{l} \\
& \&=x_{2}^{*}+\frac{R_{s}}{L_{q}} x_{2}+p \frac{L_{d}}{L_{q}} x_{1} x_{3}+p \frac{1}{L_{q}} \phi_{f} x_{1}-\frac{1}{L_{q}} v_{d c} u_{1} \\
& \&=x_{3}^{*}+\frac{R_{s}}{L_{d}} x_{3}-p \frac{L_{d}}{L_{q}} x_{1} x_{2}-\frac{1}{L_{d}} v_{d c} u_{2}
\end{aligned}
$$

Speed regulator: Consider the following Lyapunov function candidate $v_{1}=\frac{1}{2} e_{1}^{2}$ its derivative is given by the following equation:

$$
\&=e_{1} \&=e_{1}\left(x_{1}^{*}-\frac{p \phi_{f}}{j} x_{2}-\frac{f}{j} x_{1}-\frac{1}{J} T_{l}\right)
$$

In order that the derivative of the test is still negative, it must take the derivative of the form $\&=-c_{1} e_{1}^{2}$, where $c_{1}>0$; is a positive design parameter introduced by the backstepping method, which must always be positive and non-zero to meet the stability criteria of Lyapunov function. Following the backstepping approach and in order to ensure the tracking speed stability, the virtual control $x_{2}^{*}$ is chosen as follow:

$$
x_{2}^{*}=\frac{j}{p \phi_{f}}\left(+\frac{f}{j} x_{1}+\frac{1}{J} T_{l}+x_{1}^{*}-c_{1} e_{1}\right)
$$

To ensure the stability and convergence of component $x_{2}$ and its $x_{2}^{*}$ Reference; we consider the second Lyapunov following function: $v_{2}=v_{1}+\frac{1}{2} e_{2}^{2}$,allowing to deduct the time derivative of the function Lyapunov;

$$
\mathbb{L}_{2}=\frac{j}{p \phi_{f}} e_{1} e_{2}-c_{1} e_{1}+e_{2} \&=-c_{2} e_{2}^{2} \quad ; c_{2} \phi 0
$$

using (24), (30), we will select the law of command $u_{1}$ as follows:

$$
u_{1}=\frac{L_{q}}{v_{d c}}\left(x_{2}^{*}+\frac{R_{s}}{L_{q}} x_{2}+p \frac{L_{d}}{L_{q}} x_{1} x_{3}+p \frac{1}{L_{q}} \phi_{f} x_{1}-c_{2} e_{2}-\frac{i}{p \phi_{f}} e_{1}\right)
$$

Id regulator: We will define the 3rd Lyapunov function to ensure the stability of $x_{3}: v_{3}=\frac{1}{2} e_{3}^{2}$ using the 22, 25, 32 the control law is given by:

$$
u_{2}=\frac{L_{d}}{v_{d c}}\left(x_{3}^{*}+\frac{R_{s}}{L_{d}} x_{3}-p \frac{L_{d}}{L_{q}} x_{1} x_{2}-c_{3} e_{3}\right)
$$




\subsection{PFC and DC Voltage Controller}

A regulator will be designed in three steps Fig.2, so that the currents $\left(x_{4 a b c}\right)$ injected into the must be sinusoidal and in phase with the system of grid voltage. By applying the backstepping control method, the control law established using equations (5-8) of which ud, uq are the actual control inputs.

By choosing $\left[x_{4 d q} x_{5 d q} x_{6 d q}\right]^{T}$ as state variables. We begin by defining the, tracking errors:

$$
\left[e_{4 d q}\right]=\left\lfloor x_{4 d q}^{*}\right\rfloor-\left[x_{4 d q}\right] ;\left[e_{5 d q}\right]=\left[x_{5 d q}^{*}\right]-\left[x_{5 d q}\right] \quad ;\left[e_{6 d q}\right]=\left[x_{6 d q}^{*}\right]-\left[x_{6 d q}\right]
$$

where $\left\lfloor x_{4 d q}^{*}\right\rfloor,\left\lfloor x_{4 d q}^{*}\right\rfloor,\left\lfloor x_{4 d q}^{*}\right\rfloor$ is the reference signals (assumed bounded and sufficiently differentiable).

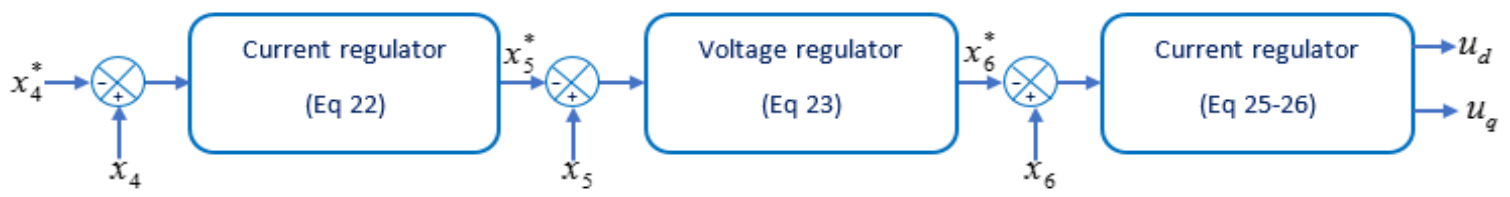

Figure 2. Block Diagram Grid-side Converter Control System

After choosing the two functions of lyapunov and following the method of backstepping we define the two virtual commands

$$
\begin{aligned}
& \left\lfloor x_{5 d q}^{*}\right\rfloor=L_{2} x_{4 d q}^{*}-r_{2}\left[x_{4 d q}\right]-\left[v_{g d q}\right]+M_{2} L_{2} x_{4 d q}-c_{4} e_{4} \\
& {\left[x_{6 d q}^{*}\right]=C\left[x_{5 d q}^{*}\right]+\left[x_{4 d q}\right]-C M\left[x_{5 d q}\right]-\left[c_{5 d q}\right]\left[e_{5 d q}\right]-\frac{1}{C}\left[e_{4 d q}\right]}
\end{aligned}
$$

Where the design parameters quantity $\left\lfloor c_{4 d q}\right\rfloor$ and $\left\lfloor c_{4 d q}\right\rfloor$ is a symmetric positive definite matrix, are given by:

$$
\left[c_{4 d q}\right]=\left[\begin{array}{cc}
c_{4 d} & 0 \\
0 & c_{4 q}
\end{array}\right] ; \quad\left[c_{5 d q}\right]=\left[\begin{array}{cc}
c_{5 d} & 0 \\
0 & c_{5 q}
\end{array}\right]
$$

\subsection{Stabilization of Subsystem (18)}

The third design step consists in choosing the actual control signals, $u_{d}$ and $u_{q}$, so that all errors $\left\lfloor e_{4 d q}\right\rfloor,\left\lfloor e_{5 d q}\right\rfloor$ converge to zero. To this end, we should make how these errors depend on the actual control signals $\left(u_{d}, u_{q}\right)$. We start focusing on $\left\lfloor e_{6 d q}\right\rfloor$;

Using (7-23) following the backstepping approach, the control law for the system is given by:

$$
\begin{aligned}
& u_{d}=-\frac{1}{v_{d c}}\left[r_{1} x_{6 d}-L_{1} \omega x_{6 q}+L_{1} d_{d d}^{*}-\frac{1}{L_{1}} e_{5 d}-c_{6} e_{6 d}\right] \\
& u_{q}=-\frac{1}{v_{d c}}\left[r_{1} x_{6 q}+L_{1} \omega x_{6 d}+L_{1} x_{q q}^{*}-\frac{1}{L_{1}} e_{5 q}-c_{6} e_{6 q}\right]
\end{aligned}
$$

\section{SIMULATION AND DISCUSSION}

The global control system described by Figure 3 is simulated using the Matlab/Simulink (V. R2015a), operating under Windows. The controlled part is a wind system including the synchronous generator and the association AC/DC/AC power converters via LCL filter. The involved elements have the 


$$
\begin{aligned}
& \text { following characteristics: } \quad c_{1}=140 s^{-1} ; c_{2}=9 e^{3} s^{-1} ; c_{3}=220 s^{-1} ; c_{4}=9 e 2 s^{-1} ; c_{5}=9 e^{3} s^{-1}, \\
& c_{6}=9 e^{3} s^{-1} \\
& \text { PMSG: } R_{s}=0.425 \Omega ; L_{d}=L_{q}=0.0084 H ; j=0.02 \text { Kg.m.m } ; \phi_{f}=0.433 w b ; p=4,
\end{aligned}
$$$$
\text { Network and filter: } v_{n}=220 \mathrm{~V} / 50 \mathrm{~Hz} ; L_{1}=L_{2}=5 e^{-3} \mathrm{H} ; r_{1}=r_{2}=50 e^{-3} \Omega \text {; }
$$

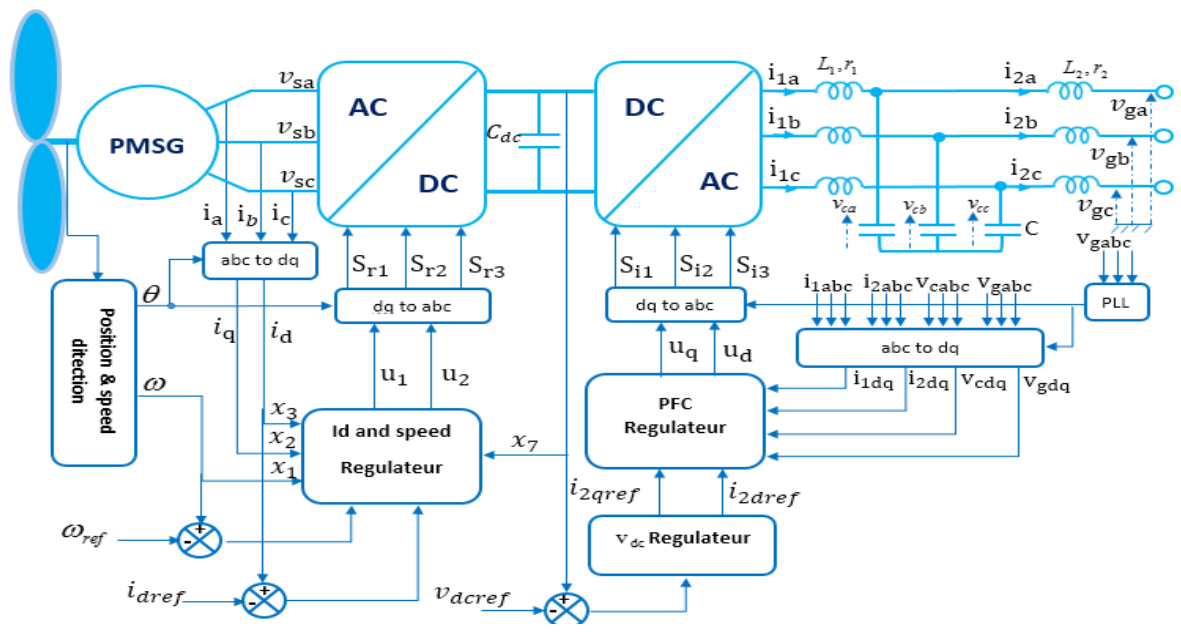

Figure 3. The General Structure Control Device of System

The performance of the regulator is evaluated by varying over time, the speed (Figure 4) and the setpoint of the DC voltage (Figure 8 ). The reference for the direct component of the stator current $i_{\text {sd }}$ set to 0 (Figure 5).

Figures 4 and 5 respectively, shows the machine speed $\Omega$ and the d-component of the stator current id. The rotational speed of the generator $\omega$ does not change a lot of value, even we varied the reference in the 0.2 second it remains practically equal to the reference value $\Omega$ ref and the value of the current isd perfectly converge to their respective reference and takes the value 0 initially fixed. Also, clearly notice in the transient regime the speed of the system with the regulator.

Figures 6 and 7 respectively, shows the q-component of the stator current iq and the electromagnetic torque. The curve of the current $i_{\text {sq }}$ tends to a constant value is of the same shape as that of the couple; it is deduced that the electromagnetic torque is directly proportional to the current isq presented in the Figure 7. Figures 8 and 9 respectively, shows represent the curve of the DC bus voltage vdc for a reference vdc_ref and the current i2 inject into the network with the supply voltage.

In the Figure 8 the value of DC-link remains stable at a constant value to give as reference. Also, the current remains all time sinusoidal and in phase with the network voltage complying with the PFC requirement demonstrate by Figure 9 et 10. In the second 0.25 we have varied the reference of the voltage vdc, it is noted that the voltage of the DC bus is enslaved quickly to its new reference, which shows the robustness of our regulator. The Figure 11, show the reactive power injected into the three - phase network (equal to zero) and the electrical power $\mathrm{P}$ produced by the machine transferred to the grid by the three-phase inverter.

From the simulation results obtained, for the wind energy system connected to the three-phase network, it can be noted from the first view, that the regulator based on the backstepping approach has a better performance than other regulator, such as directed flow control (FOC) [19], Linearization [20], Direct Torque Control (DTC) [21] and Sliding Mode approach [9], [22], especially in dynamic regime, when the controlled part is subjected to perturbations and variations of system parameters (our case), the algorithms of the classical [23] control using proportional, integral and derivative controllers remain incapable of control such nonlinear system. For so-called sophisticated control laws, there is a major problem which is the necessity of using a mechanical sensor (speed, load torque). This imposes an additional cost and increases the complexity of assemblies. For sliding-mode control, there are technological and physical limitations, such as switching delays or small-time constants at the actuator, which is why a Chattreing phenomenon appears on the sliding surface, this one characterizes by strong oscillations around the surface of commutation; 
Where we can observe in all the figures presented in our simulations basead on backstepping approach that the response time is very short so that the signals restored to the maximum values, so this rapid correction is of the speed or currents or voltages translated the continuation of our system and assured the performance of our regulator in the injection part the power to the network it is observed that our regulator respects the characteristics of our grid that it is the frequency or the phase, on the one hand, of on the other hand, the power injected into the network, we note that the reactive power tends towards a zero value and the active power reacts with the speed variation of the generator when the speed reaches the maximum the power is totally transmitted to the network.

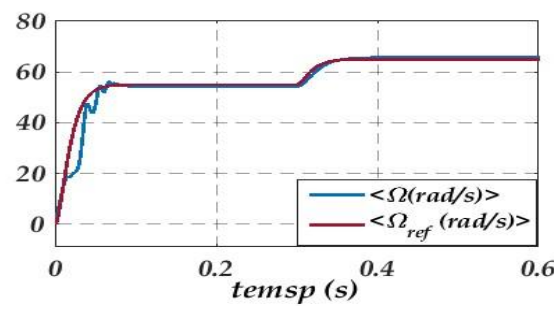

Figure 4. Rotor Speed (Rad/s) and it's Reference

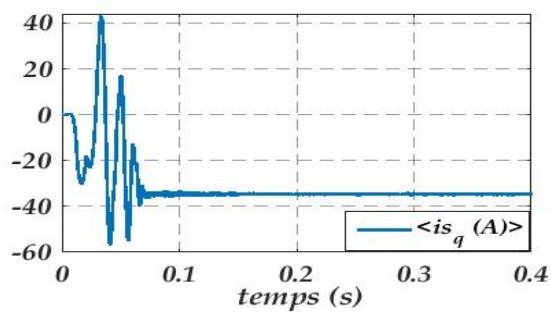

Figure 6. Q'axis Stator Current iq

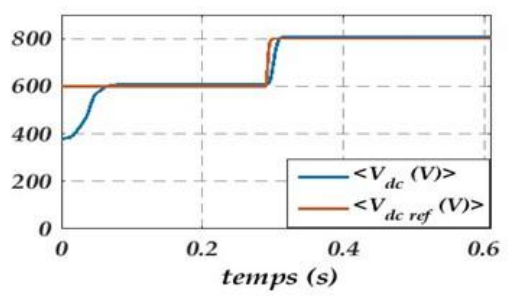

Figure 8. DC-link Voltage vdc

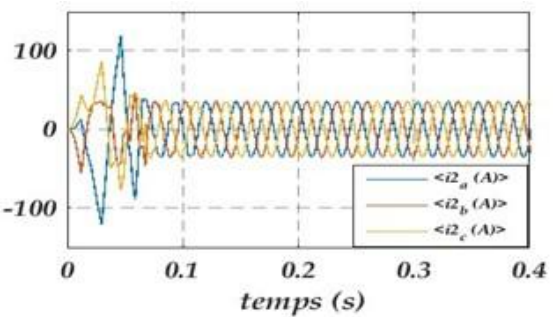

Figure 10. Output Current i2abc

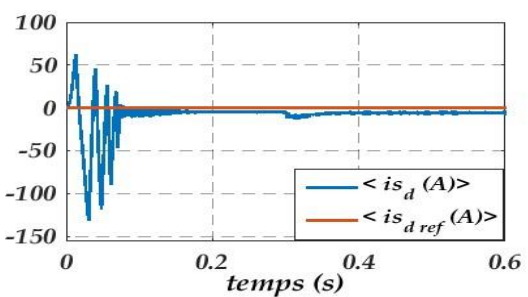

Figure 5. D'axis Stator Current id and it's Reference

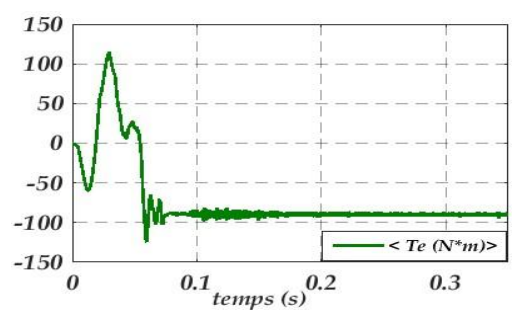

Figure 7. Electromagnetic Torque Te

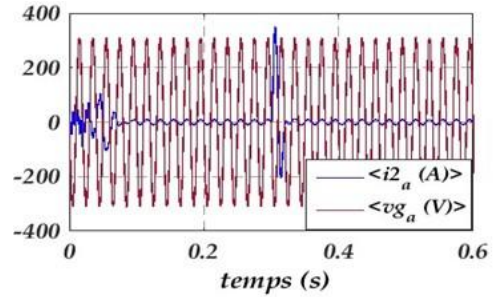

Figure 9. Unitary Power Factor (P F C)

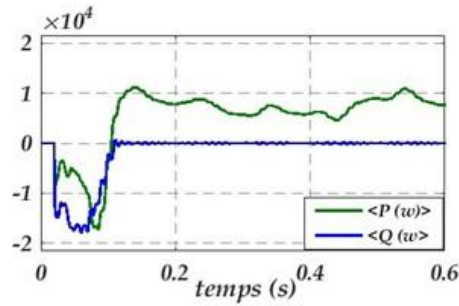

Figure 11. Active and Reactive Power 


\section{CONCLUSION}

In this paper, we have considered the problem of controlling the wind turbine synchronous generator connected to the power network through power electronic AC/DC/AC converters connected to the grid via LCL filter. The system dynamics have been described by the averaged $6^{\text {th }}$ order nonlinear state-space model (1-3),(5-8). Based on such a model, the Lyapunov stability and averaging theory are used to design nonlinear controller defined by equations $(19,20,27,28)$. the later guarantees quite interesting average performances; It is formally established that the control objectives are actually achieved in average with a quite satisfactory accuracy. Speed following his reference perfectly, the tracking quality is quite satisfactory as the response time is small after the change the wind speed, the current injected into the network remains sinusoidal all the time and in phase with the voltage of the network complying with the requirement PFC., the continuous bus DC-link follows a constant reference value. The formal results are confirmed by several simulations.

\section{REFERENCES}

[1] Bianchi, F.D., Mantz, R.J., and De Battista, H. (2007). The Wind and Wind Turbines. Springer.

[2] Rolan, A., Luna, A., Vazquez, G., Aguilar, D., and Azevedo, G. (2009). Modeling of a variable speed wind turbine with a permanent magnet synchronous generator. In 2009 IEEE International Symposium on Industrial Electronics, 734-739. IEEE.

[3] Yin, M., Li, G., Zhou, M., and Zhao, C. (2007). Modeling of the wind turbine with a permanent magnet synchronous generator for integration. In Power Engineering Society General Meeting, 2007. IEEE, 1-6. IEEE.

[4] Karthikrajan Senthilnathan, K. Iyswarya Annapoorani, "A Review on Back-to-Back Converters in Permanent Magnet Synchronous Generator based Wind Energy Conversion System" Indonesian Journal of Electrical Engineering and Computer Science Vol 2, No 3: June 2016

[5] Belloni, F., Chiumeo, R., Gandolfi, C., and Villa, A. (2014). "Simulation model of a permanent magnet synchronous generator for grid studies". In International Conference on Renewable Energies and Power Quality (ICREPQ14).

[6] Haque, M.E., Negnevitsky, M., and Muttaqi, K.M. (2010). A novel control strategy for a variable-speed wind turbine with a permanent-magnet synchronous generator. IEEE transactions on industry applications, 46(1), 331339.

[7] Camara, M.M.S., Camara, M.B., et al. Modélisation et commande d'une génératrice synchrone à aimant permanant pour la production et l'injection des énergies offshores dans un réseau. In Symposium de Génie Electrique 2014.

[8] Kechich, A. and Mazari, B. (2008). La commande par mode glissant : Application à la machine synchrone `a aimants permanents (approche linéaire). Afrique Science, 4(1), 21-37.

[9] Ding, Z., Wei, G., and Ding, X. (2014). Speed identification and control for permanent magnet synchronous motor via sliding mode approach. Systems Science \& Control Engineering: An Open Access Journal, 2(1), 161-167.

[10] Aimene, M., Payman, A., and Dakyo, B. (2014). Commande par platitude d'un système de conversion d'energie éolienne à vitesse variable connectée au réseau. In Symposium de G'enie Electrique 2014.

[11] Krstic, M., Kanellakopoulos, I., and Kokotovic, P.V. (1995). Nonlinear and adaptive control design. Wiley.

[12] Wang, X., Yuvarajan, S., and Fan, L. (2010). Mppt control for a pmsg-based grid-tied wind generation system. In North American Power Symposium (NAPS), 2010, 1-7. IEEE.

[13] Trejos-Grisales, L., Guarnizo-Lemus, C., and Serna, S. (2014). Overall description of wind power systems. Ingenier'1a y Ciencia, 10(19), 99-126.

[14] Wallmark, O. (2004). On control of permanent-magnet synchronous motors in hybrid-electric vehicle applications.

[15] J. Dannehl, C. Wessels, and F.W. Fuchs, Limitations of Voltage-Oriented PI Current Control of Grid-Connected PWM Rectifiers With LCL Filters, IEEE Transactions On Industrial Electronics, Vol. 56, No. 2, February 2009.

[16] Y. Boussairi, A.Abouloifa, A.Hamdoun, and C. Aouadi, Backsetepping Controller of Grid Connected Wind Energy Conversion System with Power Factor Correction, International Journal of Computer and Information Technology (ISSN: 2279 0764) Volume 03 Issue 05, September 2014

[17] El Magri, A., Giri, F., Abouloifa, A., and Chaoui, F.Z. (2010). Robust control of synchronous motor through ac/dc/ac converters. Control Engineering Practice, 18(5), 540-553.

[18] M. Pahlevaninezhad, S. Eren, A. Bakhshai, P. Jain, Maximum Power Point Tracking of a Wind Energy Conversion System Using Adaptive Nonlinear Approach Control Engineering Practice 18 (2010) 540553.

[19] Hasif Aziri, Fizatul Aini Patakor, Marizan Sulaiman, Zulhisyam Salleh, "Comparison Performances of Indirect Field Oriented Control for Three-Phase Induction Motor Drives" International Journal of Power Electronics and Drive Systems Vol 8, No 4: December 2017

[20] Kuroe Y., K. Okamura, H. Nishidai, and T. Maruhashi. (1998). „Optimal speed control of synchronous motors based on feedback linearization ". International Conference on Power Electronics and Variable-Speed Drives, pp $328-331$

[21] Pyrhonen O., M. Niemela, J. Pyrhonen, and J. Kaukonen, (1998). "Excitation control of DTC controlled salient pole synchronous motor in field weakening range ${ }^{e}$. International Workshop on Advanced Motion Control, AMC '98, Coimbra, pp 294- 298.

[22] Larbi M'hamed, Gherabi Zakaria, Doudar Khireddine, "A Robust Sensorless Control of PMSM Based on Sliding Mode Observer and Model Reference Adaptive System" International Journal of Power Electronics and Drive Systems, Vol 8, No 3: September 2017 
[23] Jagdish Gangadharrao Chaudhari, Sanjay Bhauraoji Bodkhe, Mohan V. Aware, Proportional Integral Estimator of the Stator Resistance for Direct Torque Control Induction Motor Drive ." International Journal of Power Electronics and Drive Systems, Vol 8, No 4: December 2017

\section{BIOGRAPHIES OF AUTHORS}

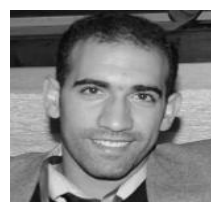

Yasser Boussiari received the MASTER degree in information processing from Faculty of Science Ben m'sik, University of Hassan II Casablanca in 2013. He is preparing his phd degree in the field of automatic, renewable energy, Power electronics at Faculty of Science Ben m'sik, TI Laboratory, University of Hassan II

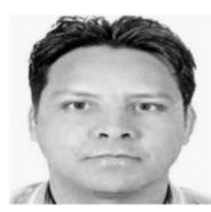

Abdelmajid Abouloifa received the Aggregation of Electrical Engineering from the Ecole Normale Supérieure de l'Enseignement Technique, Rabat, Morocco, in 1999, the Ph.D. Degree in control engineering from the University of Caen Basse-Normandie, Caen, France and from Mohammed V University, Rabat, Morocco in 2008. Currently, he is a Professor of Higher Education at the Faculty of Sciences Ben M'Sik, University Hassan Ii Morocco Casablanca. His research interests include high-frequency power converter topologies, power-factor-correction techniques, power supplies, and nonlinear control

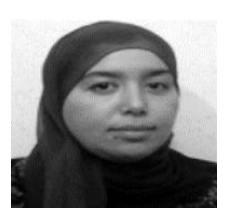

Ibtissam Lachkar received the graduate degree from the Ecole Normale Supérieure de l'Enseignement Technique, Rabat, Morocco, in 1995 and the Diplôme d'Etudes Supérieures Approfondies from the Ecole Mohammadia d'Ingénieurs (EMI), Rabat, in 2005. She received his Phd from EMI. Currently, she is a Professor at École nationale supérieure d'électricité et mécanique.

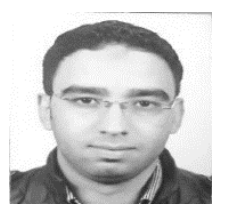

Chaouqi Aouadi received the MASTER degree in information processing from Faculty of Science Ben m'sik, University of Hassan II Casablanca in 2013. He is preparing his phd degree in the field of automatic, renewable energy, Power electronics at Faculty of Science Ben m'sik, TI Laboratory, University of HASSAN II

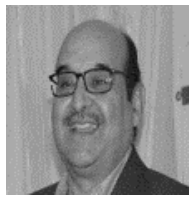

Abdelatif Hamdoun is a Professor of Higher Education at the Faculty of Sciences Ben M'Sik, University Hassan Ii Morocco Casablanca. Where he founded, in the early nineties of the last century, the Information Processing Laboratory. He is interested in the design of automatic systems for data acquisition and information processing 